Published in final edited form as:

Cell Tissue Res. 2017 April ; 368(1): 79-92. doi:10.1007/s00441-016-2513-8.

\title{
Cementogenic genes in human periodontal ligament stem cells are downregulated in response to osteogenic stimulation while upregulated by vitamin $\mathrm{C}$ treatment
}

\author{
Philippe Gauthier ${ }^{1,2}$, Zongdong $\mathrm{Yu}^{3}$, Quynh T. Tran ${ }^{4}$, Fazal-Ur-Rehman Bhatti ${ }^{3}$, Xiaofei \\ Zhu $^{3,5}$, and George T.-J. Huang ${ }^{1,2,6}$ \\ ${ }^{1}$ Department of Endodontics, Henry M. Goldman School of Dental Medicine, Boston University, \\ Boston, MA 02118, USA \\ ${ }^{2}$ Faculté de médecine dentaire, Département d'endodontie, Université Laval, Québec, QC G1V \\ OA6, Canada \\ ${ }^{3}$ Department of Bioscience Research, College of Dentistry, University of Tennessee Health \\ Science Center, Memphis, TN 38163, USA \\ ${ }^{4}$ Department of Preventive Medicine, College of Medicine, University of Tennessee Health \\ Science Center, Memphis, TN 38105, USA \\ ${ }^{5}$ VIP Dental Service and Geriatric Dentistry, School and Hospital of Stomatology, Peking \\ University, Beijing, China \\ ${ }^{6}$ Lab, Cancer Research Building, University of Tennessee Health Science Center, 19 S. \\ Manassas St. Lab Rm 225, Office 222, Memphis, TN 38163, USA
}

\section{Abstract}

Regeneration of periodontal tissues, particularly cementum, is key to regaining periodontal attachment and health. Human periodontal ligament stem cells (hPDLSCs) have been shown to be a good cell source to regenerate periodontal tissues. However, their subpopulations and the differentiation induction in relation to cementogenic lineages is unclear. Thus, we aim to examine the expression of cementum-associated genes in PDLSC subpopulations and determine the effect of broadly used osteogenic stimulus or vitamin $\mathrm{C}(\mathrm{VC})$ on the expression of cementogenic and osteogenic genes in PDLSCs. Our real-time quantitative polymerase chain reaction (qPCR) analysis showed that cementogenic marker cementum attachment protein (CAP) expressed only

Correspondence to: George T.-J. Huang.

Philippe Gauthier and Zongdong Yu contributed equally to this work.

Electronic supplementary material The online version of this article (doi:10.1007/s00441-016-2513-8) contains supplementary material, which is available to authorized users.

Authors' contributions PG and ZY designed and performed the experimental work, acquired, assembled, analyzed the data and drafted/revised the manuscript. QTT analyzed, interpreted the data, performed statistical analysis and wrote/revised part of the manuscript. FURB and XZ performed some of the experimental work, assembled, analyzed the data and drafted/revised part of the manuscript. GTJH conceived, designed, performed experimental works and supervised the overall project, analyzed and interpreted the data and finalized the manuscript. All authors have read and approved the manuscript for publication.

Compliance with ethical standards

Competing interests The authors declare that they have no competing interests. 
slightly higher in STRO-1 ${ }^{+} / \mathrm{CD} 146^{+}$, STRO-1 ${ }^{-} / \mathrm{CD} 146^{+}$and STRO-1 ${ }^{-} / \mathrm{CD} 146^{-}$subpopulations than in the original cell pool, while cementum protein 1 (CEMP1) expression in these subpopulations was not different from the original pool. Notably, under the stimulation with osteogenic differentiation medium, CAP and CEMP1 were down-regulated while osteogenic markers bone sialoprotein (BSP) and osteocalcin (OCN) were upregulated. Both CAP and CEMP1 were upregulated by VC treatment. Transplantation of VC-treated PDLSCs into immunocompromised mice resulted in forming significantly more ectopic cementum- and bonelike mineral tissues in vivo. Immunohistochemical analysis of the ectopic growth showed that CAP and CEMP1 were mainly expressed in the mineral tissue and in some cells of the fibrous tissues. We conclude that osteogenic stimulation is not inductive but appears to be inhibitory of cementogenic pathways, whereas VC induces cementogenic lineage commitment by PDLSCs and may be a useful stimulus for cementogenesis in periodontal regeneration.

\section{Keywords}

Periodontal ligament stem cells; Cementum attachment protein; Cementum protein 1; Osteogenic induction; Vitamin C

\section{Introduction}

The periodontal ligament (PDL) plays a pivotal role in the maintenance of a healthy root function in relation to its supporting bone (Melcher 1976). The PDL harbors periodontal ligament stem cells (PDLSCs) (Seo et al. 2004) that have been shown to express typical mesenchymal stem cell (MSC) markers such as STRO-1, CD13, CD29, CD44, CD59, CD90, CD146 and CD105 (Huang et al. 2009; Yu et al. 2015). PDLSCs form colonyforming unit-fibroblasts (CFU-Fs) with the potential to differentiate into multiple cell lineages in cultures as well as generate ectopic cementum-/PDL-like tissues in vivo (Gay et al. 2007; Huang et al. 2009; Seo et al. 2004; Yu et al. 2015). PDLSCs have the capacity to regenerate periodontium thereby restoring periodontal defects, as demonstrated in large animal studies such as swine using either an autologous or allogenic cell source (Ding et al. 2010; Liu et al. 2008; Menicanin et al. 2014). A case report has shown that patients with periodontal bone loss treated with PDL progenitors regained periodontal attachment with significant pocket reduction and no adverse effects were observed (Feng et al. 2010).

PDLSCs appear to participate in the formation of cementum on the root surface, PDL and bone (Isaka et al. 2001; Seo et al. 2004). Therefore, PDLSCs may give rise to cementoblasts, PDL fibroblasts and osteoblasts. From the perspective of periodontal regeneration, cementogenesis is an important step because new cementum on the root surface is needed to re-establish the new fibrous attachment formed by the regenerated PDL (Saygin et al. 2000). There are two markers that have been found to be expressed in cementogenic cells: cementum attachment protein (CAP) and cementum protein 1 (CEMP1; also called CP23). Both markers have been identified in progenitor cells of the PDL as well as in cementoblasts (Alvarez-Pérez et al. 2006; Liu et al. 1997). CAP, as a collagen-like protein, is restricted to periodontal cell lineages (BarKana et al. 2000; Metzger et al. 1998). CAP is localized in the cementum matrix, PDL and perivascular cells of alveolar bone (Arzate et al. 1992). CEMP1, 
a non-collagen protein, is highly expressed by cementoblasts and subpopulations of the PDL located in the paravascular zone in the periodontium (Alvarez-Pérez et al. 2006). It promotes octacalcium phosphate crystal nucleation during the biomineralization process (VillarrealRamírez et al. 2009).

A recent study has shown that tissue-nonspecific alkaline phosphatase (ALP)-positive PDL cells express higher levels of CEMP1 than ALP-negative cells, indicating that $\mathrm{ALP}^{+} \mathrm{PDL}$ cells are potentially a subpopulation of cementogenic progenitors (Komaki et al. 2012). It has also been considered that cementogenic progenitors are derived from the pool of PDLSCs. STRO-1 and CD146 subpopulations of PDLSCs appear to participate in the formation of cementoblasts in the inflamed condition in vivo (Chen et al. 2006). As indicated above, cemenotogenesis plays an important role in cell-based periodontal regeneration, thus identifying subpopulations in PDLSCs, or an approach to enhance PDLSC commitment into cementogenic lineages may help periodontal regeneration. In the present study, we aim to examine the levels of cementum-associated CAP and CEMP1 in different sub-populations of human (h) PDLSCs including ALP ${ }^{+}, \mathrm{STRO}-1^{+}$and CD146 ${ }^{+}$ cells and to testwhether the commonly used osteogenic stimulus can induce cementogenic genes both in vitro and in vivo.

\section{Materials and methods}

\section{Cell cultures}

PDL tissues were removed from extracted third molars ( $n=20$ teeth) of healthy patients between 14 and 30 years old in the Oral Surgery Clinics at Boston University (BU) or University of Tennessee Health Science Center (UTHSC). The patient sample collection in this study was based on approved exempt protocols by the Institutional Review Board (IRB) of BU (\#H-28882) and UTHSC (12-01937-XM); no patient consents were needed. The tissues were minced into $1 \times 1 \times 1 \mathrm{~mm}$ fragments, digested in collagenase/dispase and filtered through a $70-\mu \mathrm{m}$ strainer to obtain single-cell suspensions as described previously (Huang et al. 2010; Seo et al. 2004; Yu et al. 2015). Seeded cells were grown in a-minimum essential medium (a-MEM; Life Technologies/GIBCO BRL, Gaithersburg, MD, USA) supplemented with $10 \%$ fetal bovine serum (FBS), $2 \mathrm{mM} \mathrm{L-Glutamine,} 100 \mu \mathrm{M} \mathrm{L}$-ascorbic acid-2-phosphate and antibiotic/antimycotic agents as the regular growth medium (GM; pH 8.1); and maintained under $5 \% \mathrm{CO} 2$ at $37^{\circ} \mathrm{C}$. The formation of CFU-F was observed and allowed to expand for passaging. These heterogeneous population of PDLSCs isolated from each donor/tooth were grown separately without mixing with cells from a different donor/ tooth. Heterogeneous population of PDLSCs were split (1:3 ratio) at $\sim 80 \%$ subconfluence for passaging.

\section{Immunocytofluorescence analysis}

The following primary antibodies were used: mouse anti-bovine: CAP IgG1 (detects CAP of human and bovine origin) and goat anti-human CEMP1 IgG1. Secondary antibodies included goat anti-mouse IgG1 Alexa Fluor 594 and donkey anti-goat IgG1 Alexa Fluor 594. All detailed information on the antibodies is listed in Supplemental Table 2. 
Cells grown in chamber glass slides ( 8 wells) or in culture plates were washed with phosphate-buffered saline (PBS) and fixed with $100 \%$ ice-cold methanol for 7-10 min. After PBS washing, cells were blocked with $5 \%$ goat serum in PBS or in blocking buffer [32.5 mM NaCl, $3.3 \mathrm{mM} \mathrm{Na}_{2} \mathrm{HPO}_{4}, 0.76 \mathrm{mM} \mathrm{KH}_{2} \mathrm{PO}_{4}, 1.9 \mathrm{mM} \mathrm{NaN}_{3}, 0.1 \%$ (w/v) bovine serum albumin (BSA), $0.2 \%(\mathrm{v} / \mathrm{v})$ Triton-X 100, $0.05 \%(\mathrm{v} / \mathrm{v})$ Tween 20 and $5 \%$ goat serum] for $30 \mathrm{~min}$. The primary antibody was then added directly to cells and incubated for $1 \mathrm{~h}$ at room temperature and washed with PBS for 3 times, each for 5 min on a rocker. After the PBS wash, a secondary antibody in the blocking buffer was added and incubated for $1 \mathrm{~h}$ at room temperature in the dark. Subsequently, cell nuclei were stained with 4', 6diamidino-2-phenylindole dihydrochloride (DAPI) for $3 \mathrm{~min}$. Images were analyzed under a fluorescence microscope.

\section{Flow cytometry}

Subconfluent cells were harvested for analysis and the anti-bodies used were the following: primary antibody: anti-STRO-1 PerCP Cy5.5, CD73, CD90, CD105 and CD146 all mouse anti-human; mouse anti-bovine CAP IgG; goat anti-human CEMP1 IgG; secondary antibody: goat anti-mouse IgG (FITC) and mouse anti-goat IgG FITC; with non-immune, isotype-matched control antibodies: conjugated mouse IgG or IgM (Invitrogen) and goat IgG. All antibody information is listed in Supplemental Table 3.

For direct single staining of cell surface antigens, cell aliquots $\left(2-8 \times 10^{5}\right.$ cells $)$ were washed with $1 \%$ BSA in PBS, re-suspended in a buffer (0.1\% FBS in PBS) for 15 min at room temperature and incubated with conjugated antibodies according to the manufacturer's recommendations. For intracellular antigens (CAP and CEMP1), single cell suspensions were first fixed in $4 \%$ paraformaldehyde in PBS for $10 \mathrm{~min}$, washed with the buffer, permeabilized in $0.1 \%$ Triton-X100 for 10 min, washed with the buffer again and incubated with the antibodies for $1 \mathrm{~h}$ at $4{ }^{\circ} \mathrm{C}$ in the dark, then washed twice and re-suspended in $1 \%$ BSA in PBS (staining buffer) for analysis on a flow cytometer (LSRII flowcytometer; BD Biosciences) using the FlowJo X software (BD Biosciences).

If double-staining was used, the antibody mouse anti-STRO-1 IgM PerCP cy5.5 was incubated with the primary antibody mouse anti-CD146 IgG1. The cells were washed twice and then incubated with the secondary antibody goat anti-mouse IgG FITC. After washing, cells were then resuspended in staining buffer for analysis.

\section{Cell sorting}

Heterogeneous population of PDLSCs were considered as the cell "pool" (unsorted cells) before cell sorting to separate STRO- $1^{+}$, STRO $-1^{-}, \mathrm{CD} 146^{+} / \mathrm{STRO}-1^{+}, \mathrm{CD} 146^{+} / \mathrm{STRO}-1^{-}$ and $\mathrm{CD} 146^{-} / \mathrm{STRO}^{-1^{-}}$subpopulations; the same protocol and anti-bodies described above for flow cytometry were used (Supplemental Table 4 lists antibody information). Cells were not fixed nor permeabilized. Approximately $5 \times 10^{6}$ cells were used for STRO- 1 sorting and $10^{7}$ cells for STRO-1 and CD146 sorting. All procedures were completed in sterile conditions. The cells were sorted using a MoFlo High Speed Cell Sorter [fluorescenceactivated cell sorting (FACS); Beckman Coulter]. After which, cells were plated into 6-well plates $\left(5 \times 10^{4} /\right.$ per well) and grown to $80-90 \%$ confluence for subsequent analysis. 
For sorting $\mathrm{ALP}^{+} / \mathrm{ALP}^{-}$cells, $10^{7}$ cells were washed twice with a sorting buffer (5\% FBS in culture medium), resuspended in a blocking buffer ( $10 \mu \mathrm{g} / \mathrm{mL}$ mouse IgG in PBS) and incubated for $15 \mathrm{~min}$ at room temperature. Mouse anti-human ALP (APC-ALP) antibody $\left(10 \mu \mathrm{L} / 10^{6}\right.$ cells) was added into the cells and vortexed. After incubation for $60 \mathrm{~min}$ at $4{ }^{\circ} \mathrm{C}$ (in the dark), cells were washed twice in a sorting buffer (5\% FBS in cell culture medium) and resuspended in the same buffer for FACS (FACS Aria Cell Sorter; BD Biosciences). Sorted cells were collected in a collecting buffer ( $20 \%$ FBS in culture medium), further cultured and frozen or passaged until experimentation.

$\mathrm{ALP}^{+} / \mathrm{ALP}^{-}$cells were also separated by magnetic beads cell separation with MACS Separator kits (MACS Miltenyi Biotec, Auburn, CA, USA) according to the manufacturer's instruction. Cells $\left(10^{7}\right)$ were harvested and washed in a cell sorting buffer $(0.5 \%$ BSA and 2 mM EDTA in PBS, pH 7.2), centrifuged and resuspended in the blocking buffer, as used in FACS sorting, for $15 \mathrm{~min}$ at room temperature. APC-ALP antibody was then added to the cells and incubated in the dark for $60 \mathrm{~min}$ at $4{ }^{\circ} \mathrm{C}$. Cells were then washed twice in the sorting buffer and resuspended in $80 \mu \mathrm{L}$ of sorting buffer. Twenty $\mu \mathrm{L}$ of Anti-APC microbeads were then added to the cells and mixed well followed by incubation for $15 \mathrm{~min}$ at $4{ }^{\circ} \mathrm{C}$ in the dark. Subsequently, cells were washed in buffer and resuspended in $500 \mu \mathrm{L}$ of sorting buffer and loaded onto a prepared column placed on a separator. The collected cells that flowed through the column were $\mathrm{ALP}^{-}$cells. The column was then removed from the separator and placed on a collection tube. The $\mathrm{ALP}^{+}$cells were collected from the column after adding the buffer and firmly pushing the plunger into the column. We found that using FACS or MACS yielded similar results (Yu et al. 2015). In the present study, FACS was used for the data in Figs. 1, 2a and 3c and all other data that required sorting were from the MACS method.

\section{Osteogenic differentiation}

Cells were seeded into 12-well plates, grown to $~ 70-80 \%$ confluence and incubated in osteogenic differentiation medium (OM; pH 8.0) containing osteogenic components: DMEM medium (Life Technologies/GIBCO BRL) plus $10 \mathrm{nM}$ dexamethasone, $10 \mathrm{mM} \beta$ glycerophosphate, $50 \mu \mathrm{g} / \mathrm{ml}$ ascorbate phosphate, $10 \mathrm{nM} \mathrm{1,25}$ dihydroxyvitamin $\mathrm{D}_{3}\left(\mathrm{VD}_{3}\right)$ and 10\% FBS (Alongi et al. 2010; Liao et al. 2011); for various time points and then processed for analysis. All cell cultures were maintained under $5 \% \mathrm{CO} 2$ at $37^{\circ} \mathrm{C}$. This differentiation medium has been broadly used for osteogenic studies for osteoblast differentiation. PDLSCs may undergo both odontogenic (cementogenic) and/or osteogenic differentiation. Therefore, the osteogenic differentiation medium may possess both lineages of induction. The medium was changed every 3 days. Cultures were harvested for reverse transcription (RT)-polymerase chain reaction (PCR) and RT-real time/quantitative (q)PCR. Some samples were tested in pilot studies and stained with Alizarin Red S after osteogenic stimulation (See Supplemental materials).

\section{RT-PCR and RT-qPCR}

The cells were harvested and total RNA isolated for first-strand cDNA synthesis. PCR was conducted using Platinum Blue PCR superMix (Invitrogen) with forward/reverse primers and cDNA template followed by 30 cycles of amplification. The sequence of primers is 
listed in Supplemental Table I and the detail procedures in Supplemental Materials and Methods.

For RT-qPCR, the SYBR green method was used as described by the manufacturers. Briefly, cDNA template was mixed with SYBR Green PCR Master Mix, forward/reverse primers and sterile distilled water to a final volume. The reaction mixture was placed in a 96-well plate, covered, centrifuged and then placed in a Real-Time PCR System for 40 cycles of amplification (detail procedures in Supplemental Materials and Methods).

\section{Western blot}

hPDLSCs $\left(\sim 10^{6}\right.$ cells) were harvested and lysed in ice-cold RIPA buffer (Thermo Scientific, Rockford, IL, USA) that contained $1 \%$ protease inhibitor (Thermo Scientific). Lysates were centrifuged at 12,000 rpm for $20 \mathrm{~min}$. The supernatant was collected and protein concentrations were determined using a BCA (bicinchoninic acid) protein assay (Bio-Rad, Hercules, CA, USA). Laemmli sample buffer (Bio-Rad) was added to the lysate that was then heated to $95^{\circ} \mathrm{C}$ for $10 \mathrm{~min}$. Forty $\mu \mathrm{g}$ of total cellular protein was loaded and fractionated on a $12 \%$ SDS-PAGE (BiO-Rad), transferred onto a nitrocellulose membrane (Biorad), blocked with $5 \%$ nonfat dry milk and incubated with primary antibodies against CAP (mouse anti-bovine CAP) and CEMP1 (rabbit anti-human CEMP1). Horseradish peroxidase-conjugated secondary antibodies were then added and the antigens were detected by enhanced chemiluminescence (ECL; GE Healthcare, Buckinghamshire, UK). Membranes were reprobed with anti-a-Tubulin antibody (Calbiochem, Billerica, MA, USA) for control of equal loading. Antibody information is listed in Supplemental Table 5. The luminescent protein bands were detected by X-ray films.

\section{In vivo transplantation}

hPDLSCs $\left(2-3 \times 10^{6}\right)$ were treated or not treated with vitamin C (VC) $(20 \mu \mathrm{g} / \mathrm{mL})$ at subconfluence for 1 week. Cells were then trypsinized (all over-confluent at the point) and mixed with the carrier hydroxyapatite and tri-calcium phosphate (HA/TCP) powder (20 mg; Berkeley Advanced Biomaterials, Berkeley, CA, USA) in a 2 ml-tube and incubated with rotation for $90 \mathrm{~min}$ at $37^{\circ} \mathrm{C}$. The mixture $\left(2-3 \times 10^{6}\right.$ cells/20 mg HA/TCP) was pelleted measuring $\sim 5 \times 5 \times 4 \mathrm{~mm}$ to be transplanted into the back of a NOD.CB17-Prkdc ${ }^{\text {scid } / \mathrm{J}}$ mouse under general anesthesia with isoflurane inhalation (female, $\sim 7$ weeks old) (Jackson Labs, Bar Harbor, ME, USA). Each pelleted mixture was carefully transferred using a periodontal flap elevator instrument into the subcutaneous space (created by incision) of the mouse. Three mice were used for the study and each mouse received 4 transplants of mixtures (two on each side; one at the shoulder region and one at the hind leg region). Mice were given the analgesic carprofen $5-10 \mathrm{mg} / \mathrm{kg}$ and all survived the experimental interval without complications. Three months after implantation, the mice were euthanized using compressed $\mathrm{CO}_{2}$ gas followed by a physical method and transplants removed for histological analysis. All animal procedures followed a protocol (\#2081) approved by the Institutional Animal Care and Use Committee (IACUC) at UTHSC. 


\section{Histological examination and mineral tissue quantitation}

The resected tissues were fixed with $10 \%$ phosphate-buffered formalin and decalcified with 0.5 M EDTA ( $\mathrm{pH}$ 8.0) for 4 weeks. The samples were dehydrated, embedded in paraffin blocks and sectioned $(4 \mu \mathrm{m})$ for hematoxylin and eosin (H\&E) staining. Some of the sections were used for immunohistochemical analysis. Quantitative analysis of mineral tissues was performed using ImageJ. Each tissue sample was sectioned into 9-12 sections and each section was analyzed using ImageJ. The entire area of HA/TCP granules and the small amount of tissues between the granules in each section was considered as the total area (Supplemental Fig. 1a). The areas of the newly formed mineral tissues within the HA/TCP/ tissue mass were measured (Supplemental Fig. 1b) and the \% was calculated against the total area. Due to the irregularity in the shape of the granules and tissues, they were outlined using the freehand selection method and the areas were measured by ImageJ (Alongi et al. 2010; Jaha et al. 2016).

\section{Immunohistochemistry}

Deparaffinized sections were immersed in $3 \% \mathrm{H}_{2} \mathrm{O}_{2} /$ methanol for 10 min to quench endogenous peroxidase activity followed by antigen retrieval with $0.05 \%$ trypsin (Corning, Manassas, VA, USA) for $10 \mathrm{~min}$ at $37{ }^{\circ} \mathrm{C}$. After rinsing in distilled water, the sections were incubated with prediluted normal horse serum (Vector, Burlingame, CA, USA) for $30 \mathrm{~min}$ at room temperature to block non-specific protein binding sites. The sections were then incubated overnight at $4{ }^{\circ} \mathrm{C}$ with primary antibodies, and prediluted biotinylated horse antimouse/rabbit IgG (H+L) (Vector) was used as a secondary antibody. For visualization of reaction products, sections were treated with 3, 3'-diaminobenzidine (DAB Substrate Kit; Vector) and then counterstained with Modified Mayer's Hematoxylin (Richard-Allan Scientific, Kalamazoo, MI, USA).

Primary antibodies used were as follows: mouse anti-bovine CAP, rabbit anti-human periostin (H-300), mouse anti-human bone sialoprotein (BSP); and rabbit anti-human CEMP1; and mouse anti-human mitochondria. Normal (preimmune) mouse/rabbit IgG as control was used under the same conditions as the primary antibodies. Antibody information is listed in Supplemental Table 6.

\section{Data analysis}

The strategy for the statistical analysis was to test the null hypothesis that the outcome measurements are not different among the groups of interest in each of the experiments. One-way ANOVA was used to compare single factors among three or more groups. Twoway ANOVA was used to examine the effects of two independent factors and their interaction effect on the outcome. When data were collected from different donors, mixedeffects model was performed treating the donor as a random effect. If the main and/or interaction effect was found to be statistically significant, post hoc comparisons were examined by the Tukey HSD test. We calculated the adjusted $p$ values using the Benjamini and Hochberg procedure. If the adjusted $p$ value was smaller than the false discovery rate 0.05 , the test was considered significant. Shapiro-Wilk's and Levene's tests were used to test the normality and homoscedasticity of the residuals, respectively, for each model. Log2 transformation was applied when the normality assumption was not met. When the 
assumption was not met, non-parametric procedures such as Kruskal-Wallis or Friedman's two-way nonparametric ANOVA were performed. Non-parametric comparisons for all pairs were performed using the Steel-Dwass method. Data are reported as mean \pm SEM. All analyses were performed using JMP ${ }^{\circledR}$ Pro 10.0.0 and SAS 9.3 (SAS Institute, Cary, NC, USA).

\section{Results}

\section{Subpopulations and their expression of CAP and CEMP1}

We examined the STRO-1/CD146 subpopulations and determined if these cells expressed different levels of cementum-associated markers. Levels of CAP and CEMP1 in the pool or subpopulations of PDLSCs were determined using flow cytometry (Fig. 1a, a'). Neither were detectable in either the pool, STRO- $1^{+} / \mathrm{CD} 146^{+}$, STRO- $1^{-} / \mathrm{CD} 146^{+}$, or STRO-1 ${ }^{-/}$ CD146 ${ }^{-}$subpopulations by flow cytometry (Fig. 1b, c). Using immunocytofluorescence, we attempted to detect CAP and CEMP1. As shown in Fig. 1d', d", CAP was only detected in one of the passage 2 PDLSC cultures. CEMP1 was never detected by such an immunocytofluorescence analysis.

With the qPCR approach, both markers were detected (Fig. 1e, e'). There was generally no significant difference in the expression levels of $C A P$ and $C E M P 1$ between sorted subpopulations of STRO- $1^{+}$vs STRO-1 ${ }^{-}$, STRO- $1^{+} / \mathrm{CD} 146^{+}$vs STRO-1-/CD146-, except that $C A P$ in subpopulations was slightly higher than in the pool (1.1- to 1.4-fold).

With qPCR, we further compared the cementogenic marker expression in $\mathrm{ALP}^{+}$and $\mathrm{ALP}^{-}$ subpopulations. Both $C A P$ and $C E M P 1$ expression were slightly higher (1.2- to 1.3-fold; however, there were no significant differences, $p>0.05)$ in $\mathrm{ALP}^{+}$compared with $\mathrm{ALP}^{-}$cells at lower passages 3-5 (Fig. 2a) and only $C A P(p<0.05)$ and not $C E M P 1$, was slightly higher in $\mathrm{ALP}^{+}$than $\mathrm{ALP}^{-}$at the higher passage 8 ( 1.2-fold; Fig 2b). Whereas $C A P$ expression fluctuated but remained at a similar level at passage 16 compared to that at passage 4, CEMP1 appeared to decrease at higher passages. (Fig. 2c). With western blot analysis, we were able to detect CEMP1 but not CAP (Fig. 2d). The protein levels of CEMP1 detected by western blot at different passages did not correlate with those found by qPCR.

\section{Osteogenic stimulation downregulated $C A P$ and $C E M P 1$ expression}

To determine whether $C A P$ and $C E M P 1$ expression is regulated by osteogenic induction (under $\mathrm{OM}$ ), we first conducted a time-course experiment of heterogeneous PDLSCs from one donor and samples analyzed by RT-PCR (Supplemental Fig. 2). CAP expression gradually increased over time in the control group and did not appear to be affected by the osteogenic induction. CEMP1 expression in the control group increased as early as day 3 and remained high until day 15 . The osteogenic induction appeared to decrease $C E M P 1$ expression. $A L P$ expressed at low levels at day 0 and gradually increased at day 15 . The osteogenic induction appeared to decrease $A L P$ expression after day 7 compared to the control counterparts. RUNX2 was expressed at moderate levels throughout and was not affected by the osteogenic induction. BSP expression was below detectable levels 
throughout the experimental period. $O C N$ expression increased after 7 days of induction and remained until the end of the experimental period on day 21 .

We then conducted qPCR for heterogeneous PDLSCs from three donors and found that CEMP1 expression in PDLSCs was downregulated under the osteo-inductive condition compared to controls and $C A P$ decreased in either the control or the induced group after 15 days (Fig. 3a). All osteogenic markers tested were upregulated over time especially after osteogenic induction compared to day 0 (Fig. 3b). Further analysis of $C A P$ and $C E M P 1$ expression levels between the pool, $\mathrm{ALP}^{+}$and $\mathrm{ALP}^{-}$groups was performed. We found that, while $C A P$ expression fluctuated, $C E M P 1$ expression was reduced in all cell groups by osteogenic stimulus especially after 3 weeks (Fig. 3c).

Under the OM stimulation, cells continued to proliferate until confluence (normally within 2-3 days after OM addition) as shown in Supplemental Fig. 3. The cell morphology of PDLSCs at low passages normally showed triangular, rectangular or spindle shapes and were often elongated (Supplemental Fig. 3a-a"). After osteogenic stimulation, cells became over-confluent and it was difficult to observe individual cell morphology. Over time, mineral deposits began to appear either scattering or forming aggregates in cell cultures

(Supplemental Fig. 3b, b'). The longer the stimulation, the more mineral deposits could be seen, especially when revealed by Alizarin Red S stain (Supplemental Fig. 3c).

\section{Vitamin $C$ treatment increased CAP and CEMP1 expression}

We next tested the treatment of PDLSCs with VC and determined its effects on $C A P$ and $C E M P 1$ expression. It has been reported that VC treatment of PDLSCs promotes cell sheet formation and tissue regeneration (Wei et al. 2012, 2013). We found that both genes were increased following VC treatment based on our qPCR analysis. $C A P$ induction reached more than 2 -fold in 1 week and decreased thereafter $(p<0.0001)$ (Fig. 4a). CEMP1 also increased by 3 -fold after 1 week and remained high until the end of the experiment period ( 3 weeks). Additionally, the $C E M P 1$ levels in the control cultures also significantly increased over time $(p<0.0001)$ (Fig. 4b). After VC treatment of PDLSCs for 1 week, we sorted cells into subpopulations $\mathrm{ALP}^{+}$and $\mathrm{ALP}^{-}$and observed that $\mathrm{ALP}^{-}$cells appeared to have a higher level of $C E M P 1$ than the $\mathrm{ALP}^{+}$; however, the difference was not statistically significant with $p=0.0558$ after adjusting for multiple hypothesis testing (Fig. 4c). This $p$ value suggests that there might be a difference if larger samples were tested.

We also tested osteogenic marker gene expression after VC treatment. We found that $R U N X 2$ levels decreased over time in both control and VC-treated groups (Fig. 4d). BSP showed some increase after VC treatment in the first 2 weeks. The control groups appeared unchanged over time (Fig. 4e). OCN appeared increased over time in both control and VCtreated groups (Fig. 4f). However, no difference was detected from those osteogenic genes between control and treatment groups using stringent statistical tests. The stemness gene expression NANOG and OCT4 was reduced in the VC-treated group compared to the control indicating that VC treatment caused the cells to be more differentiated (Fig. $4 \mathrm{~g}, \mathrm{~h}$ ). The cells continued to grow after $\mathrm{VC}$ addition to cultures and reached an over-confluent state at the time of harvest. Morphologically, cell groups treated with $\mathrm{VC}$ were similar to those non-treated controls (Supplemental Fig. 4). 


\section{Vitamin $\mathbf{C}$ treatment increased mineral tissue formation in vivo}

In order to determine whether $\mathrm{VC}$ treatment can induce ectopic cementum formation in vivo, we conducted a well-established experimental procedures by mixing PDLSCs (VC-treated for 1 week) with the osteoinductive material HA/TCP and transplanted the mixture into the subcutaneous space of immunocompromised mice (Seo et al. 2004). We observed mineral tissue formation around the HA/TCP granules and observed that the capacity to form osteoid tissues varied among cells from different donors. As shown in Fig. 5a, cells from donor 2 was weak in such tissue formation. Based on quantitative analysis, the VC-treated cells consistently and significantly formed more osteoid tissues than the non-treated across the donors. The difference was significant either within each donor (1.5- to 4.6-fold higher; $p<$ 0.01 or $<0.001$ ) or when compared altogether ( $p<0.0001$ ) (Fig. 5b). Many pieces of mineral tissue in the samples were bone-like with a heavier eosin stain versus some areas of mineral tissue that were lightly stained indicating less calcification (Fig. 5c, d). One limitation of such a histological analysis of mineral tissue formation around the HA/TCP is the level of mineralization of the tissues, which can only be observationally determined by the characteristics of the structures and staining intensity.

It was noted that the more heavily stained mineral tissue appeared to have fewer or no wellaligned cells next to it and the cells were usually flat, whereas the lightly stained mineral tissue tended to have well-aligned round to cuboidal cells along its surface (Fig. 6d, d' red arrowheads). Furthermore, the less calcified mineral tissue tended to show less-organized fiber orientations. More calcified mineral tissue showed lamellar lines (Supplemental Fig. 5). Some areas of the mineral tissue showed Sharpey's fiber-like structures throughout all samples examined (Fig. 5e).

\section{Detection of cemento- and osteo-genic markers by immunohistochemistry}

We also performed immunohistochemistry to detect the expression of cementogenic and osteogenic gene products. Positive immunoreactivities of CAP, CEMP-1 and periostin were observed (Fig. 6; Supplemental Fig. 6). CAP detection was associated with newly formed mineral tissues. CEMP1 and periostin were also detected in the mineral tissues and in some cells of the fibrous ligament-like connective tissues. In general, BSP staining in the mineral tissue was minimal to moderate and much weaker compared to CAP, CEMP1 and periostin, although many cells (cementoblasts-like) next to the mineral tissues or in the fibrous tissues were strongly BSP-positive. To determine that these regenerated tissues were at least in part produced by the transplanted hPDLSCs, we used antibodies against human mitochondria. As shown in Fig. 6 and Supplemental Fig. 6, cells against the newly formed mineral tissues orHA/TCP granules were stained positively by the antibodies and some cells in the adjacent PDL-like were more weakly stained. This indicates that these cells in the regenerated tissues are transplanted human cells.

\section{Discussion}

Our present study has demonstrated that in the in vitro culture system, the osteogenic stimulus induces PDLSC osteogenic gene expression while downregulating cementogenic genes $C E M P 1$ and $C A P$. The $\mathrm{ALP}^{+}$subpopulation of PDLSCs expresses slightly higher 
levels of $C E M P 1$ and/or $C A P$ than $\mathrm{ALP}^{-}$. VC treatment or over-confluence can increase cementogenic gene expression. After VC treatment, the $\mathrm{ALP}^{+}$subpopulation no longer expresses a higher CAP than $\mathrm{ALP}^{-}$. The VC treatment also increases the cementum-like mineral tissue formation in vivo. CAP and CEMP1 can be detected in these newly formed ectopic tissues.

As mentioned above, cememtogenesis is critical for periodontal regeneration. Cell-based therapy using PDLSCs has shown promise (Feng et al. 2010; Liu et al. 2008). Although immortal cell lines from PDLSCs have been established (Hasegawa et al. 2010; Torii et al. 2015), they are more useful as study models than for use for clinical therapy. Primary PDLSCs are needed for cell-based therapy for periodontal regeneration. Identifying a subpopulation or a simple treatment condition to allow transplanted PDLSCs participating in cementogenesis is needed. It has been difficult to separate subpopulations in PDLSCs that have a potential for osteogenesis or cementogenesis. The osteogenic induction by the commonly used protocol caused the reduction of $C A P$ and $C E M P 1$ expression as shown in our present study. This indicates that the osteogenic stimulus induces PDLSCs to commit toward osteoblasts while suppressing cementogenic pathways. Overexpressing CEMP1 in PDL cells, on the other hand, can enhance cementogenesis while suppressing osteogenesis of PDL cells as shown in other reports (Komaki et al. 2012).

ALP plays a role in bone matrix mineralization and has been used as an early marker gene during osteogenesis and dentinogenesis (Hessle et al. 2002; Liu et al. 2005; Tsai et al. 2009; Viereck et al. 2002). In the search for cementum-forming populations within PDLSC populations, Komaki et al. (2012) identified that CEMP1 is more expressed in $\mathrm{ALP}^{+} \mathrm{PDL}$ cells but only a little in $\mathrm{ALP}^{-}$cells (Komaki et al. 2012). However, our present study only observed a weak, if any, association in CAP expression (Fig. 2b). This discrepancy of finding could be due to donor variations or the different methods used. Chen et al. (2006) performed in situ immunohistochemical staining and observed that STRO-1 and CD146 subpopulations of PDL cells appear to participate in the formation of cementoblasts in the inflamed condition in vivo (Chen et al. 2006); however, our in vitro analysis show no association of STRO-1, CD146, or STRO-1/CD146 with CEMP1 and only a slight relationship with CAP (Fig. 1e, e').

A genetic approach by overexpressing CEMP1 in PDLSCs can induce the cementogenic phenotype in vitro (Carmona-Rodríguez et al. 2007; Komaki et al. 2012). The non-genetic approach was demonstrated that cultured PDLSC expressed CAP after 4 weeks in the presence of human recombinant CEMP1 (Hoz et al. 2012), or by stimulation with BMPs ( -2 and -7) (Torii et al. 2015). However, BMP-2 was found to reduce CEMP-1 expression in PDL cells (Komaki et al. 2012). Therefore, careful selection of protein factors is important to guide cementogenic lineages. Our data showed that, in cultured PDLSC populations, CEMP1 expression is detectable by PCR and western blot analysis and that CAP expression could be induced by longer culturing after cells became over-confluent or boosted by the addition of VC. This suggests the presence of cementogenic phenotypes in cultures without adding exogenous CEMP1. This autocrine signaling mechanism may induce some populations of PDLSCs to undergo cementogenic commitment. 
The distinction of cementogenesis versus osteogenesis in vivo after transplantation of PDLSCs has also been elusive. When mixing PDLSCs with HA/TCP and inserting into the subcutaneous space of immunocompromised mice, cementum-like, or osteoid tissues (lacking bone marrow) were observed (Menicanin et al. 2014;Moshaverinia et al. 2013; Seo et al. 2004, 2005). PDLSCs were also used to regenerate periodontium in periodontal defects in a large animal study and in a subcutaneous model in mice showing newly formed cementum-like tissue on the root surface (Akizuki et al. 2005; Flores et al. 2008; Iwata et al. 2009). Transplanted PDLSCs are capable of forming cementum-like mineral tissue on a bioroot surface (Wei et al. 2013).

While PDLSCs have been used to regenerate bone, it is unclear if the regenerated bone-like mineral tissue is bona fide bone containing bone marrow (Moshaverinia et al. 2013; Tour et al. 2012). Interestingly, regardless of $\mathrm{VC}$ treatment, we observed that many mineral tissues formed in vivo were similar between the control and $\mathrm{VC}$ groups and no bone marrow formation was detected. Our immunohistochemical analysis was able to detect CAP, CEMP1 and periostin, suggesting the regenerated tissues are cementum- and PDL-like (AlvarezPérez et al. 2006; Arzate et al. 1992; Horiuchi et al. 1999; Liu et al. 1997; Romanos et al. 2014). CAP was mainly in the newly formed mineral tissue but hardly in cells of the soft connective PDL-like tissue, which may explain why we could not detect CAP by western blots. BSP was detected in cells lining against the mineral tissues, which corresponds to the finding that BSP is expressed in cementoblasts during root development (D'Errico et al. 1997). VC treatment has multiple effects on PDLSCs, including increased production of extracellular matrix such as type I collagen and integrin $\beta 1$, as well as upregulation of stem cell markers $O C T 4, S O X 2$ and $N A N O G$ (Wei et al. 2012). This increased stemness expression appears to be overridden by the eventual differentiation toward cementogenic lineages evidenced by our current findings (Fig. 4g, h).

\section{Conclusions}

In summary, our present study indicates that the commonly used osteogenic stimulus containing dexamethasone, $\mathrm{VD}_{3}$ and $\beta$-glycerophosphate does not appear to help guide PDLSCs toward cementogenic lineages in vitro. In contrast, it does induce osteogenic marker expression. This suggests that, under such stimulus, pathways that induce more specific cementogenic genes are not induced but inhibited. VC, on the other hand, supports increased expression of cementogenic genes. Compared to genetic approaches or using recombinant proteins to induce cementogenic commitment, our finding on $\mathrm{VC}$ treatment alone for such a purpose is more feasible and safer for clinical cell-based periodontal regeneration.

\section{Supplementary Material}

Refer to Web version on PubMed Central for supplementary material. 


\section{Acknowledgments}

This work was supported in part by a grant from the National Institutes of Health R01 DE019156 (G.T.-J.H.), by an Endodontic Research Grant from the American Association of Endodontists Foundation (G.T.-J.H.) and a Research Fund from the University of Tennessee Health Science Center.

\section{Abbreviations}

$\begin{array}{ll}\text { ALP } & \text { Tissue-nonspecific alkaline phosphatase } \\ \text { BSA } & \text { Bovine serum albumin } \\ \text { BSP } & \text { Bone sialophosphoprotein } \\ \text { CAP } & \text { Cementum attachment protein } \\ \text { CEMP1 or CP23 } & \text { Cementum protein 1 } \\ \text { DAPI } & 4^{\prime}, 6 \text {-diamidino-2-phenylindole dihydrochloride } \\ \text { FACS } & \text { Fluorescence-activated cell sorting } \\ \text { hPDLSCs } & \text { Human periodontal ligament stem cells } \\ \text { MSCs } & \text { Mesenchymal stem cells } \\ \text { OCN } & \text { Osteocalcin } \\ \text { PDL } & \text { Periodontal ligament } \\ \text { RUNX2 } & \text { Runt-related transcription factor } 2\end{array}$

\section{References}

Akizuki T, Oda S, Komaki M, Tsuchioka H, Kawakatsu N, Kikuchi A, Yamato M, Okano T, Ishikawa I. Application of periodontal ligament cell sheet for periodontal regeneration: a pilot study in beagle dogs. J Periodontal Res. 2005; 40:245-251. [PubMed: 15853971]

Alongi DJ, Yamaza T, Song Y, Fouad AF, Romberg EE, Shi S, Tuan RS, Huang GT-J. Stem/progenitor cells from inflamed human dental pulp retain tissue regeneration potential. Regen Med. 2010; 5:617-631. [PubMed: 20465527]

Alvarez-Pérez MA, Narayanan S, Zeichner-David M, Rodríguez Carmona B, Arzate H. Molecular cloning, expression and immunolocalization of a novel human cementum-derived protein (CP-23). Bone. 2006; 38:409-419. [PubMed: 16263347]

Arzate H, Olson SW, Page RC, Gown AM, Narayanan AS. Production of a monoclonal antibody to an attachment protein derived from human cementum. FASEB J. 1992; 6:2990-2995. [PubMed: 1644261]

BarKana I, Narayanan AS, Grosskop A, Savion N, Pitaru S. Cementum attachment protein enriches putative cementoblastic populations on root surfaces in vitro. J Dent Res. 2000; 79:1482-1488. [PubMed: 11005732]

Carmona-Rodríguez B, Álvarez-Pérez MA, Narayanan AS, Zeichner-David M, Reyes-Gasga J, Molina-Guarneros J, García-Hernández AL, Suárez-Franco JL, Chavarría IG, Villarreal-Ramírez E, Arzate H. Human cementum protein 1 induces expression of bone and cementum proteins by human gingival fibroblasts. Biochem Biophys Res Commun. 2007; 358:763-769. [PubMed: 17509525] 
Chen SC, Marino V, Gronthos S, Bartold PM. Location of putative stem cells in human periodontal ligament. J Periodontal Res. 2006; 41:547-553. [PubMed: 17076780]

D’Errico JA, MacNeil RL, Takata T, Berry J, Strayhorn C, Somerman MJ. Expression of bone associated markers by tooth root lining cells, in situ and in vitro. Bone. 1997; 20:117-126. [PubMed: 9028535]

Ding G, Liu Y, Wang W, Wei F, Liu D, Fan Z, An Y, Zhang C, Wang S. Allogeneic periodontal ligament stem cell therapy for periodontitis in swine. Stem Cells. 2010; 28:1829-1838. [PubMed: 20979138]

Feng F, Akiyama K, Liu Y, Yamaza T, Wang TM, Chen JH, Wang BB, Huang GT, Wang S, Shi S. Utility of PDL progenitors for in vivo tissue regeneration: a report of 3 cases. Oral Dis. 2010; 16:20-28. [PubMed: 20355278]

Flores MG, Hasegawa M, Yamato M, Takagi R, Okano T, Ishikawa I. Cementum-periodontal ligament complex regeneration using the cell sheet technique. J Periodontal Res. 2008; 43:364-371. [PubMed: 18205734]

Gay I, Chen S, MacDougall M. Isolation and characterization of multipotent human periodontal ligament stem cells. Orthod Craniofacial Res. 2007; 10:149-160.

Hasegawa T, Chosa N, Asakawa T, Yoshimura Y, Ishisaki A, Tanaka M. Establishment of immortalized human periodontal ligament cells derived from deciduous teeth. Int J Mol Med. 2010; 26:701-705. [PubMed: 20878092]

Hessle L, Johnson KA, Anderson HC, Narisawa S, Sali A, Goding JW, Terkeltaub R, Millan JL. Tissue-nonspecific alkaline phosphatase and plasma cell membrane glycoprotein-1 are central antagonistic regulators of bone mineralization. Proc Natl Acad Sci U S A. 2002; 99:9445-9449. [PubMed: 12082181]

Horiuchi K, Amizuka N, Takeshita S, Takamatsu H, Katsuura M, Ozawa H, Toyama Y, Bonewald LF, Kudo A. Identification and characterization of a novel protein, periostin, with restricted expression to periosteum and periodontal ligament and increased expression by transforming growth factor beta. J Bone Miner Res. 1999; 14:1239-1249. [PubMed: 10404027]

Hoz L, Romo E, Zeichner-David M, Sanz M, Nunez J, Gaitan L, Mercado G, Arzate H. Cementum protein 1 (CEMP1) induces differentiation by human periodontal ligament cells under threedimensional culture conditions. Cell Biol Int. 2012; 36:129-136. [PubMed: 21929512]

Huang GTJ, Gronthos S, Shi S. Mesenchymal stem cells derived from dental tissues vs. those from other sources: their biology and role in regenerative medicine. J Dent Res. 2009; 88:792-806. [PubMed: 19767575]

Huang GT-J, Yamaza T, Shea LD, Djouad F, Kuhn NZ, Tuan RS, Shi S. Stem/progenitor cell-mediated de novo regeneration of dental pulp with newly deposited continuous layer of dentin in an in vivo model. Tissue Eng A. 2010; 16:605-615.

Isaka J, Ohazama A, Kobayashi M, Nagashima C, Takiguchi T, Kawasaki H, Tachikawa T, Hasegawa K. Participation of periodontal ligament cells with regeneration of alveolar bone. J Periodontol. 2001; 72:314-323. [PubMed: 11327058]

Iwata T, Yamato M, Tsuchioka H, Takagi R, Mukobata S, Washio K, Okano T, Ishikawa I. Periodontal regeneration with multilayered periodontal ligament-derived cell sheets in a canine model. Biomaterials. 2009; 30:2716-2723. [PubMed: 19201461]

Jaha H, Husein D, Ohyama Y, Xu D, Suzuki S, Huang GT, Mochida Y. N-terminal dentin sialoprotein fragment induces type I collagen production and upregulates dentinogenesis marker expression in osteoblasts. Biochem Biophys Rep. 2016; 6:190-196. [PubMed: 27158678]

Komaki M, Iwasaki K, Arzate H, Narayanan AS, Izumi Y, Morita I. Cementum protein 1 (CEMP1) induces a cementoblastic phenotype and reduces osteoblastic differentiation in periodontal ligament cells. J Cell Physiol. 2012; 227:649-657. [PubMed: 21465469]

Liao J, Al Shahrani M, Al-Habib M, Tanaka T, Huang GT. Cells isolated from inflamed periapical tissue express mesenchymal stem cell markers and are highly osteogenic. J Endod. 2011; 37:12171224. [PubMed: 21846537]

Liu HW, Yacobi R, Savion N, Narayanan AS, Pitaru S. A collagenous cementum-derived attachment protein is a marker for progenitors of themineralized tissue-forming cell lineage of the periodontal ligament. J Bone Miner Res. 1997; 12:1691-1699. [PubMed: 9333130] 
Liu J, Jin T, Ritchie HH, Smith AJ, Clarkson BH. In vitro differentiation and mineralization of human dental pulp cells induced by dentin extract. In Vitro Cell Dev Biol Anim. 2005; 41:232-238. [PubMed: 16223338]

Liu Y, Zheng Y, Ding G, Fang D, Zhang C, Bartold PM, Gronthos S, Shi S, Wang S. Periodontal ligament stem cell-mediated treatment for periodontitis in miniature swine. Stem Cells. 2008 2007-0734.

Melcher AH. On the repair potential of periodontal tissues. J Periodontol. 1976; 47:256-260. [PubMed: 775048]

Menicanin D, Mrozik KM, Wada N, Marino V, Shi S, Bartold PM, Gronthos S. Periodontal-ligamentderived stem cells exhibit the capacity for long-term survival, self-renewal, and regeneration of multiple tissue types in vivo. Stem Cells Dev. 2014; 23:1001-1011. [PubMed: 24351050]

Metzger Z, Weinstock B, Dotan M, Narayanan AS, Pitaru S. Differential chemotactic effect of cementum attachment protein on periodontal cells. J Periodontal Res. 1998; 33:126-129. [PubMed: 9553872]

Moshaverinia A, Chen C, Xu X, Akiyama K, Ansari S, Zadeh HH, Shi S. Bone regeneration potential of stem cells derived from periodontal ligament or gingival tissue sources encapsulated in RGDmodified alginate scaffold. Tissue Eng Part A. 2013

Romanos GE, Asnani KP, Hingorani D, Deshmukh VL. PERIOSTIN: role in formation and maintenance of dental tissues. J Cell Physiol. 2014; 229:1-5. [PubMed: 23702840]

Saygin NE, Giannobile WV, Somerman MJ. Molecular and cell biology of cementum. Periodontol. 2000; 24:73-98.

Seo BM, Miura M, Gronthos S, Bartold PM, Batouli S, Brahim J, Young M, Robey PG, Wang CY, Shi S. Investigation of multipotent postnatal stem cells from human periodontal ligament. Lancet. 2004; 364:149-155. [PubMed: 15246727]

Seo BM, Miura M, Sonoyama W, Coppe C, Stanyon R, Shi S. Recovery of stem cells from cryopreserved periodontal ligament. J Dent Res. 2005; 84:907-912. [PubMed: 16183789]

Torii D, Konishi K, Watanabe N, Goto S, Tsutsui T. Cementogenic potential of multipotential mesenchymal stem cells purified from the human periodontal ligament. Odontology. 2015; 103:27-35. [PubMed: 24399512]

Tour G, Wendel M, Moll G, Tcacencu I. Bone repair using periodontal ligament progenitor cell-seeded constructs. J Dent Res. 2012; 91:789-794. [PubMed: 22736447]

Tsai MT, Li WJ, Tuan RS, Chang WH. Modulation of osteogenesis in human mesenchymal stem cells by specific pulsed electromagnetic field stimulation. J Orthop Res. 2009; 27:1169-1174. [PubMed: 19274753]

Viereck V, Siggelkow H, Tauber S, Raddatz D, Schutze N, Hufner M. Differential regulation of Cbfa1/ Runx2 and osteocalcin gene expression by vitamin-D3, dexamethasone, and local growth factors in primary human osteoblasts. J Cell Biochem. 2002; 86:348-356. [PubMed: 12112004]

Villarreal-Ramírez E, Moreno A, Mas-Oliva J, Chávez-Pacheco JL, Narayanan AS, Gil-Chavarría I, Zeichner-David M, Arzate H. Characterization of recombinant human cementum protein 1 (hrCEMP1): primary role in biomineralization. Biochem Biophys Res Commun. 2009; 384:49-54. [PubMed: 19393626]

Wei F, Qu C, Song T, Ding G, Fan Z, Liu D, Liu Y, Zhang C, Shi S, Wang S. Vitamin C treatment promotes mesenchymal stem cell sheet formation and tissue regeneration by elevating telomerase activity. J Cell Physiol. 2012; 227:3216-3224. [PubMed: 22105792]

Wei F, Song T, Ding G, Xu J, Liu Y, Liu D, Fan Z, Zhang C, Shi S, Wang S. Functional tooth restoration by allogeneic mesenchymal stem cell-based bio-root regeneration in swine. Stem Cells Dev. 2013; 22:1752-1762. [PubMed: 23363023]

Yu Z, Gauthier P, Tran QT, El Ayachi I, Bhatti F-U-R, Bahabri R, Al-Habib M, Huang GTJ. Differential properties of human ALP+ periodontal ligament stem cells vs their ALP- counterparts. J Stem Cell Res Ther. 2015; 5:292. [PubMed: 26807329] 

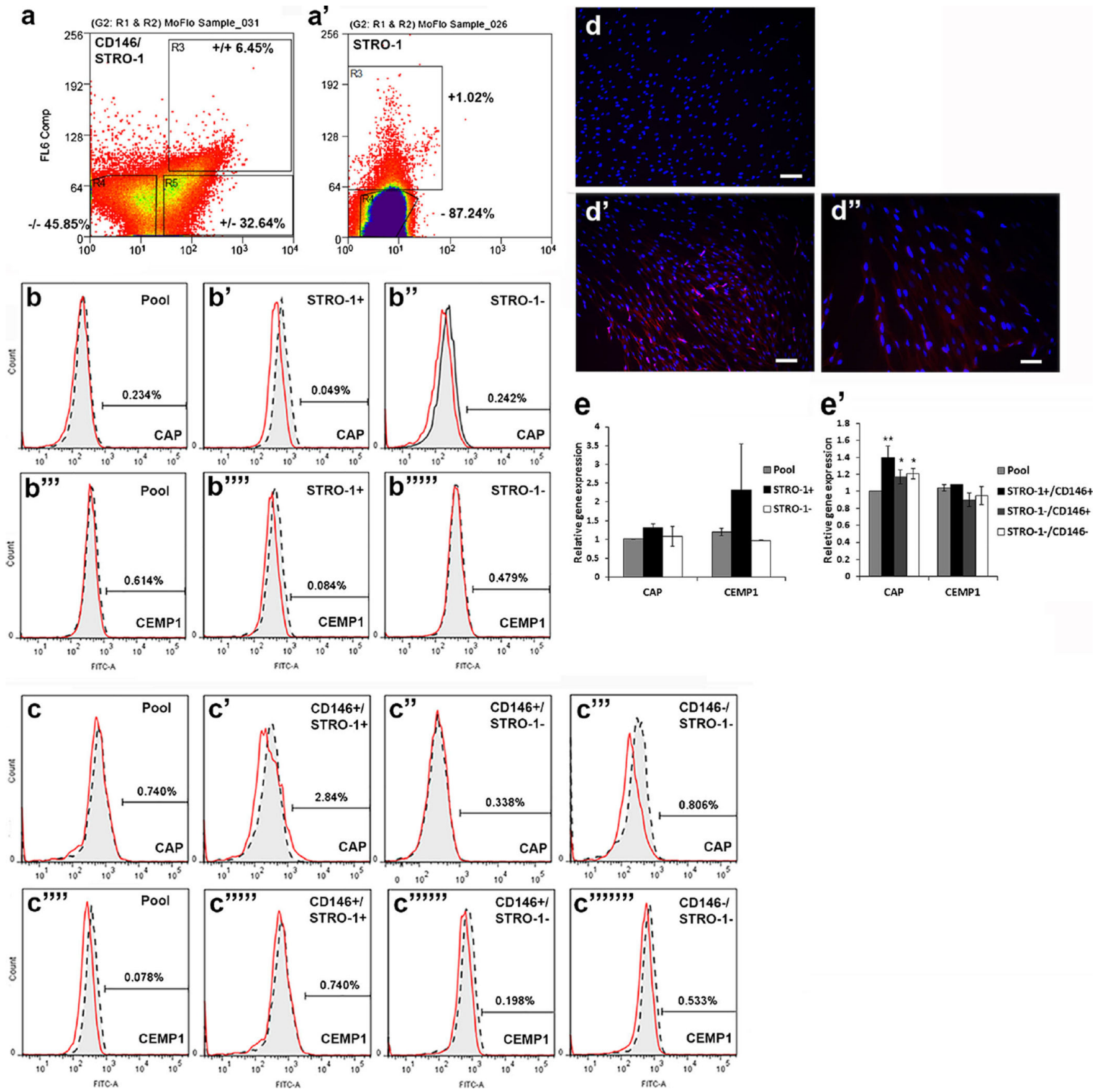

Fig. 1.

Expression of CAP and CEMP1 in PDLSC subpopulations. a, a' Fluorescence-activated cell sorting of STRO-1+, STRO-1-, STRO-1+/CD146+, STRO-1-/CD146+ and STRO-1-/ CD146- subpopulations. Cells were at passage 1 for sorting, after which cells were plated (passage 2) in culture, grown to $80 \%$ confluence and harvested for flow or qPCR analysis. $\mathbf{b}, \mathbf{c}$ Flow cytometry analysis of CAP (b-b", c-c"') and CEMP1 (b"'-b"'", $\mathbf{c}$ "'-c'"'"') in the PDLSC pool or subpopulations. d-d" Immunocytofluorescence staining of CAP. PDLSCs at passage 1 were seeded into a 96-well plate at 1 cell/well. CAP was detected in one clone. d 
is the isotype IgG control, d', d" show red fluorescence. No positive staining of CAP when heterogeneous subpopulation was used. Scale bars (d, d) $100 \mu \mathrm{m}$; (d") $50 \mu \mathrm{m}$. e, e' qPCR analysis of $C A P$ and $C E M P 1$ expression in STRO-1 (e) and STRO-1/CD146 (e') subpopulations. Significant differences between the pool and other subpopulations: ${ }^{*} p<$ $0.05 ; * * p<0.0001$. Data measured from two donors each assayed in triplicate 
a

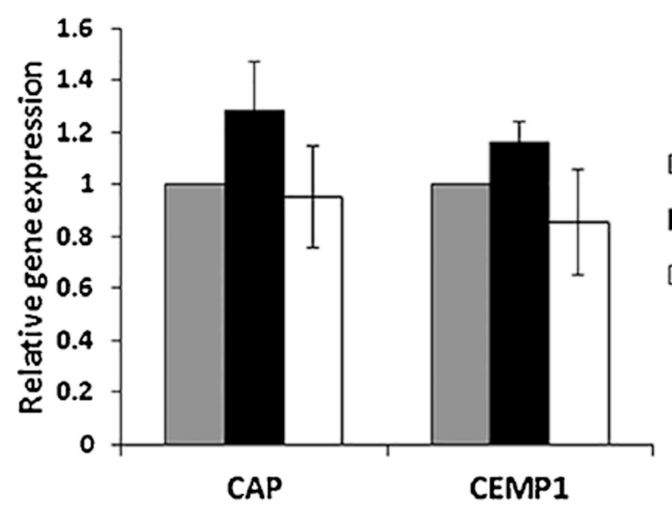

C

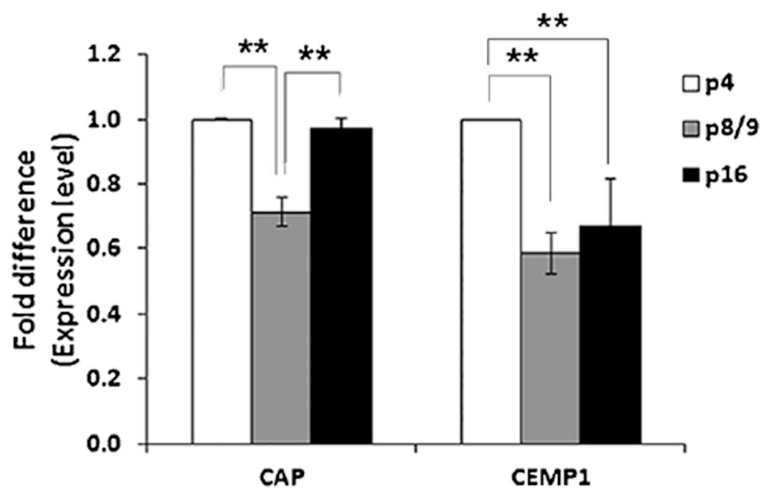

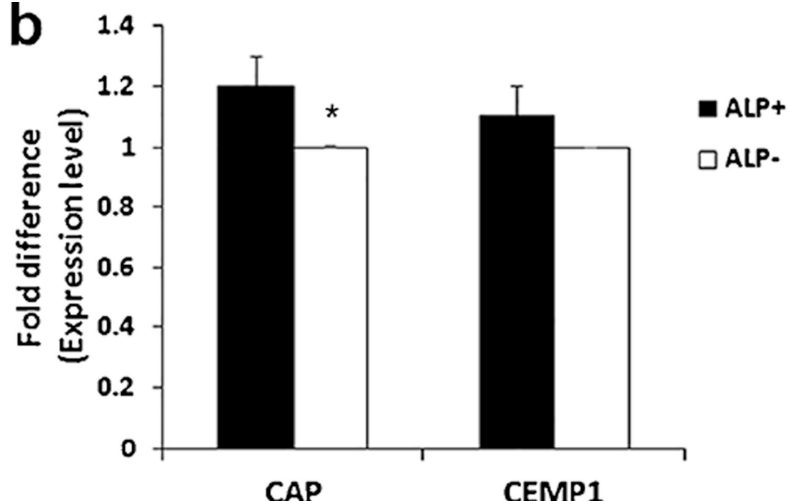

d
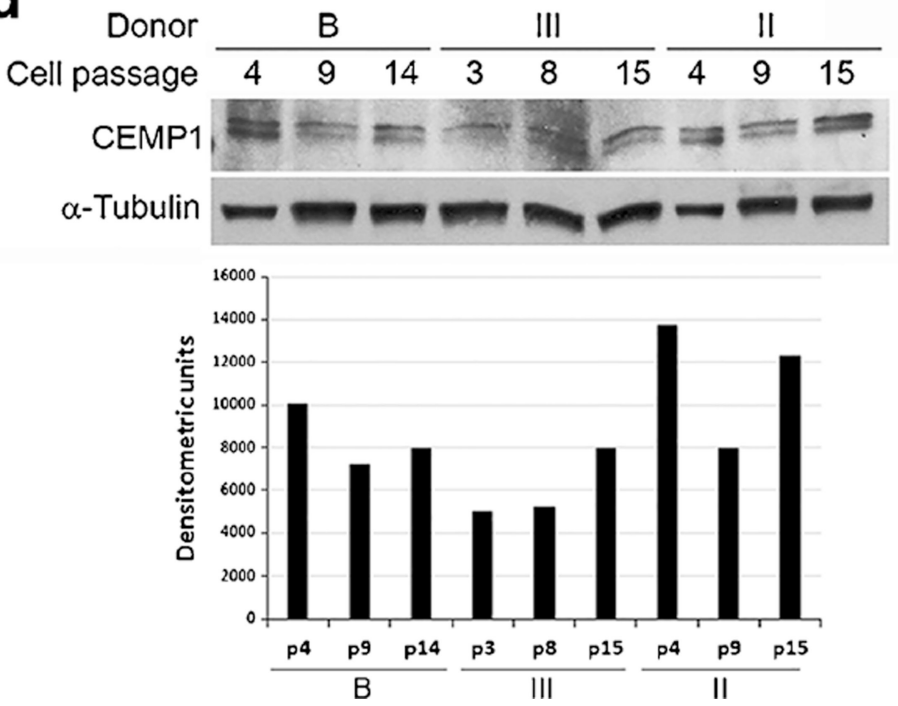

Fig 2.

Detection of CAP and CEMP1 in ALP+ and ALP- subpopulations and at different passages. a qPCR analysis of $C A P$ and $C E M P 1$ between the pool, ALP+ and ALP- subpopulations. Cells were sorted at passages 3 or 5 and cells lysed for RNA isolation. qPCR data represent mean \pm SEM of two independent experiments (cells from two donors) each performed in triplicate. $\mathbf{b}$ Expression of cementum associated genes $C A P$ and $C E M P 1$ by PDLSC subpopulations ALP+ and ALP- at passage 8. PDLSC pools were first sorted at passages 23 and the ALP- subpopulations were continuously cultured and passaged until passage 8 and sorted again to separate ALP+ and ALP- for qPCR analysis. Data represent mean \pm SEM from two different donors each assayed in triplicate. Significant differences in $C A P$ expression between ALP+ and ALP-: $F(3,8)=6.4655,{ }^{*} p=0.0034$. $\mathbf{c}$ Expression of $C A P$ and $C E M P 1$ by PDLSC pools at various passages (p4, p8 or 9 and p16). Data represent mean \pm SEM from three different donors each assayed in triplicate. Significant difference: $* p<0.001$. d Western blot analysis of CEMP1 expression in the pool of PDLSCs from three different donors (B, III and II) at different cell passages. Bottom densities of each gel band after normalization against $\alpha$-tubulin analyzed by Image $J$ 

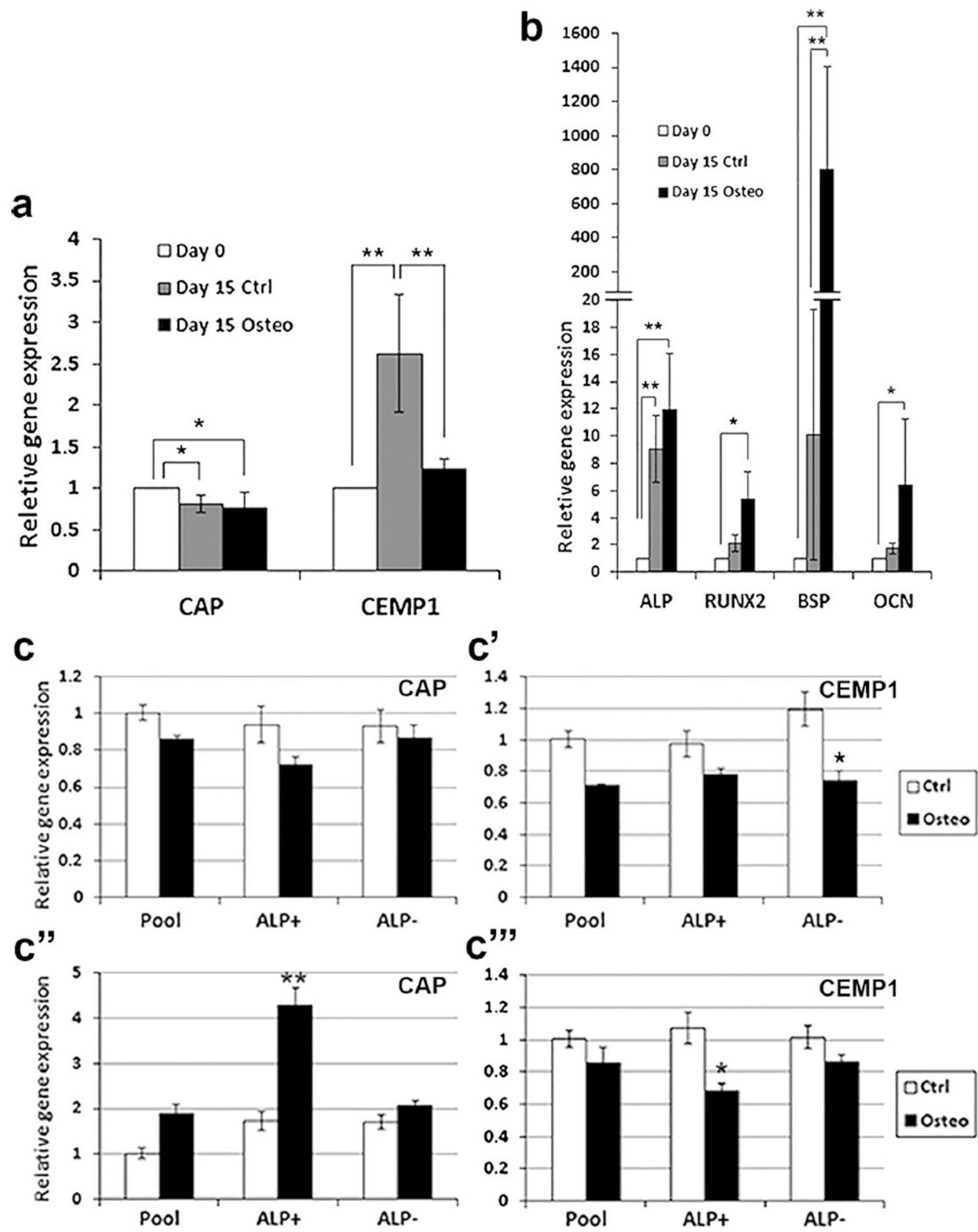

C"'
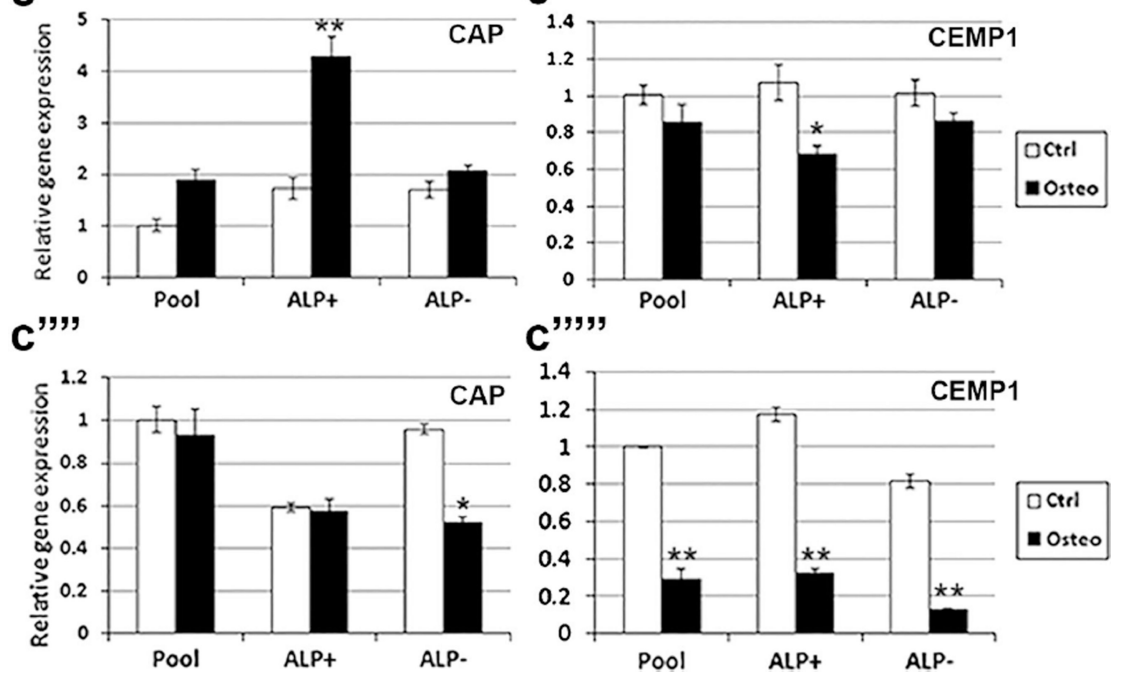

Fig 3.

Expression of cementum and osteogenic markers in PDLSCs under osteogenic induction. Heterogeneous pools of PDLSCs were stimulated in OM (osteogenic) for various time points and harvested for qPCR analysis. Cells in control group (non-induced) were grown in regular GM. a, b Expression of cememtum and osteogenic markers at days 0 and 15. Data represent mean \pm SEM of three donors ( 3 independent experiments, each performed in triplicate). Significant differences: $* p<0.05, * * p<0.0001$. c Expression of $C A P$ and CEMP1 detected by qPCR of the pool and ALP+/ALP- subpopulation PDLSCs under 
osteogenic induction for 1 (c, $\left.\mathbf{c}^{\prime}\right), 2$ (c", $\left.\mathbf{c} "\right)$ or 3 (c"', $\mathbf{c}$ '"') weeks. Representative data from one donor measured in triplicate. Significant differences between control and osteogenesis in each cell group: $* p<0.05, * * p<0.0001$ 


\section{a}

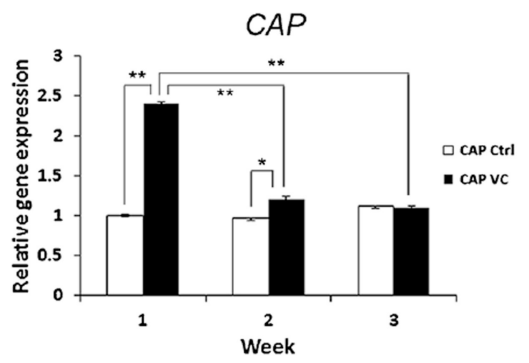

d

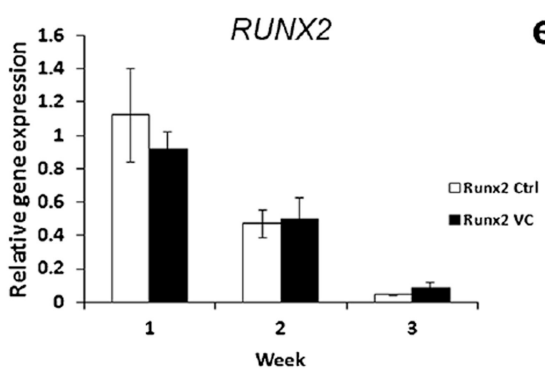

b
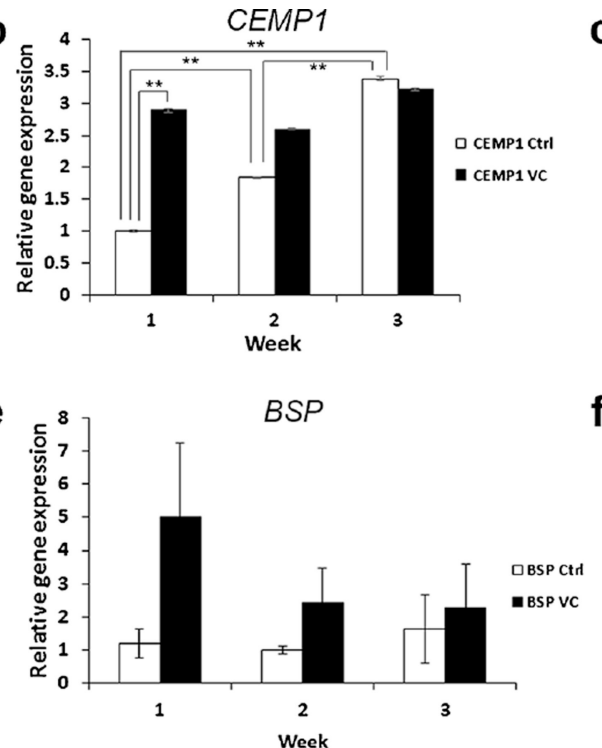

C

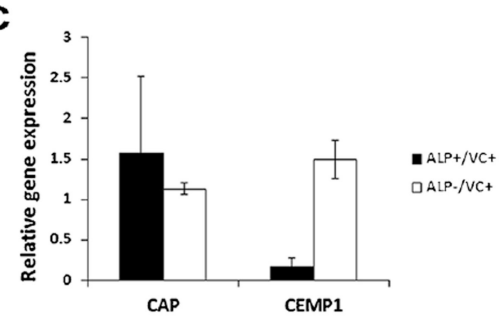

g

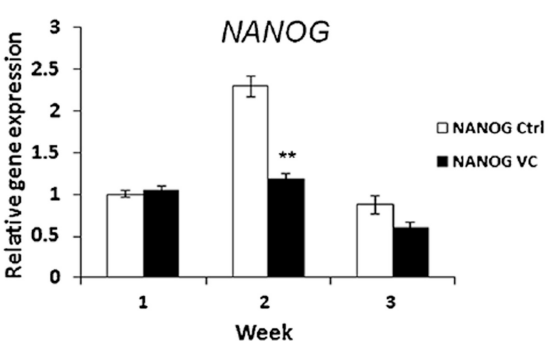

h

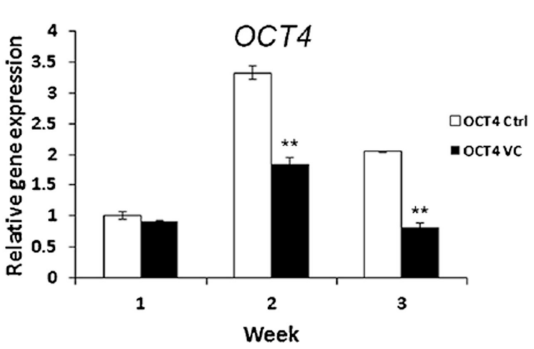

Fig. 4.

Expression of cemental markers in PDLSCs with vitamin C (VC) treatment. PDLSCs (passages 3-4) were seeded in wells of 6 well-plates and the VC group was added (20 $\mu \mathrm{g} / \mathrm{mL}$ ) at subconfluence and the control groups received no VC. At different time points after the VC addition, cells were harvested for qPCR analysis. Expression of $C A P(\mathbf{a}, p<$ $0.0001 \mathrm{~F}(5,12)=434.7178)$ and $C E M P 1(\mathbf{b}, p<0.0001, F(5,12)=1059.43)$ in PDLSCs after 1-3 weeks of VC treatment. $\mathbf{c}$ PDLSCs were cultured with VC for 1 week and sorted into ALP+ and ALP- cells for qPCR analysis of CAP and CEMP1. d-f Osteogenic markers $R U N X 2, B S P$ and $O C N$ were also detected by qPCR at the different time points. (We performed the Cochran-Mantel-Haenszel test on the ranks of fold change in each time block; there was no statistically significant difference). $\mathbf{g}$, h Stemness genes NANOG ( $p<$ $0.0001, F(5,12)=39.78$; Ctrl vs VC) and OCT4 $(p<0.0001, F(5,12)=109.15 ; \mathrm{Ctrl}$ vs VC) were detected by qPCR. Data in $(\mathbf{a}, \mathbf{b}, \mathbf{d}-\mathbf{h})$ represent mean \pm SEM from one donor assayed in triplicate. Data in (c) represent mean \pm SEM from three different donors each assayed in triplicate. Significant differences: ${ }^{*} p<0.05 ; * * p<0.0001$. PDLSCs were grown in medium absent of L-ascorbic acid 2-phospate for the VC experiments 


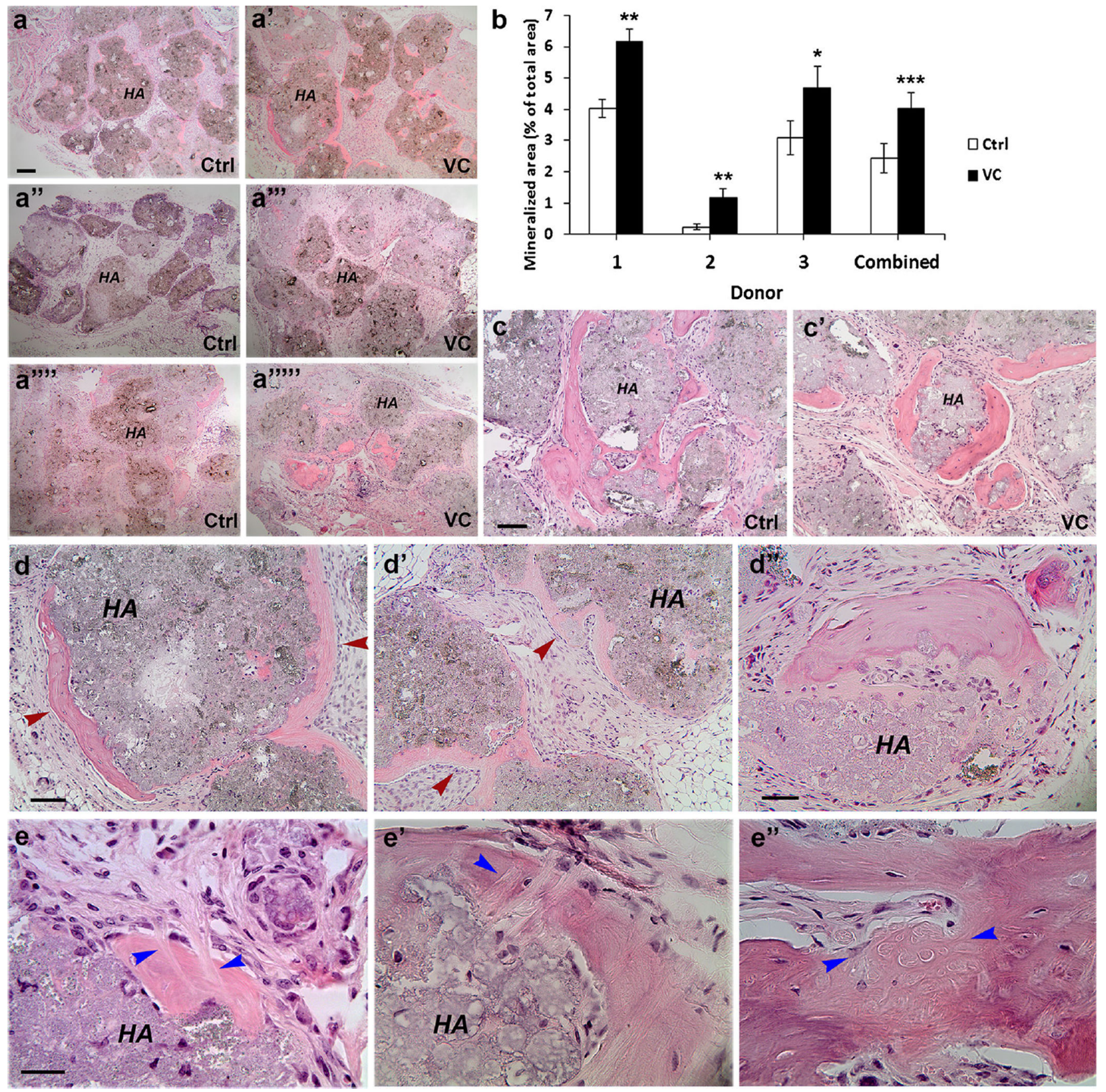

Fig. 5.

Formation of ectopic mineral tissues in vivo by PDLSCs. Cells $\left(2-3 \times 10^{6}\right)$ at passages $2-3$ treated or not treated (control) with $\mathrm{VC}(20 \mu \mathrm{g} / \mathrm{mL})$ for 1 week were mixed with $20 \mathrm{mg}$ of HA/TCP and transplanted into SCID mice. Formed tissues were harvested after 3 months and decalcified for histological analysis. a-a'"'" Mineral tissue formation around the HA/TCP granules by PDLSCs from three donors 1 (a, a'), 2 (a", a"') and 3 (a"', a"'”). b Quantitative analysis of mineral tissues. Cells from each donor were made duplicate for ectopic mineral tissue formation. There were a total of 12 tissue samples and each was 
sectioned into 9-12 sections (total 138 sections). Every section was analyzed using ImageJ as described in "Materials and methods". Data represent mean \pm SEM for each donor ( $t$ test for two-tailed $p$ values after Benjamini Hochberg adjustment; * $p<0.01$; $* *<0.001$ ) or combined for 3 donors (a mixed model with a donor and slide were random variables, treatment as a fixed variable. The treatment effect when comparing VC to control has a $* * * p$ value $<0.0001$ ). c, c' Magnified views of mineral tissues. Sample from donor 3. d-d"

Sample from donor 1, VC-treated group. Red arrowheads indicate mineral tissues. $\mathbf{d}$ Heavier mineral stain (right) versus lighter mineral stain (left). d' Light mineral stain. d" Heavy and light mineral stain located in the same mineral complex. e Collagen fibers (bundles) resembling Sharpey's fibers (blue arrowheads). Samples from (a", a"') donor 2, VC-treated; e') donor 1, control; e") donor 3, VC-treated. Ctrl: cells grown in regular medium; VC: cells treated with VC. Scale bar: (a-a'",') $200 \mu \mathrm{m}$ for all six images. Scale bars (c, c') $100 \mu \mathrm{m}$; (d, d') $100 \mu \mathrm{m}$, (d") $50 \mu \mathrm{m}$; (e-e") $30 \mu \mathrm{m}$ 

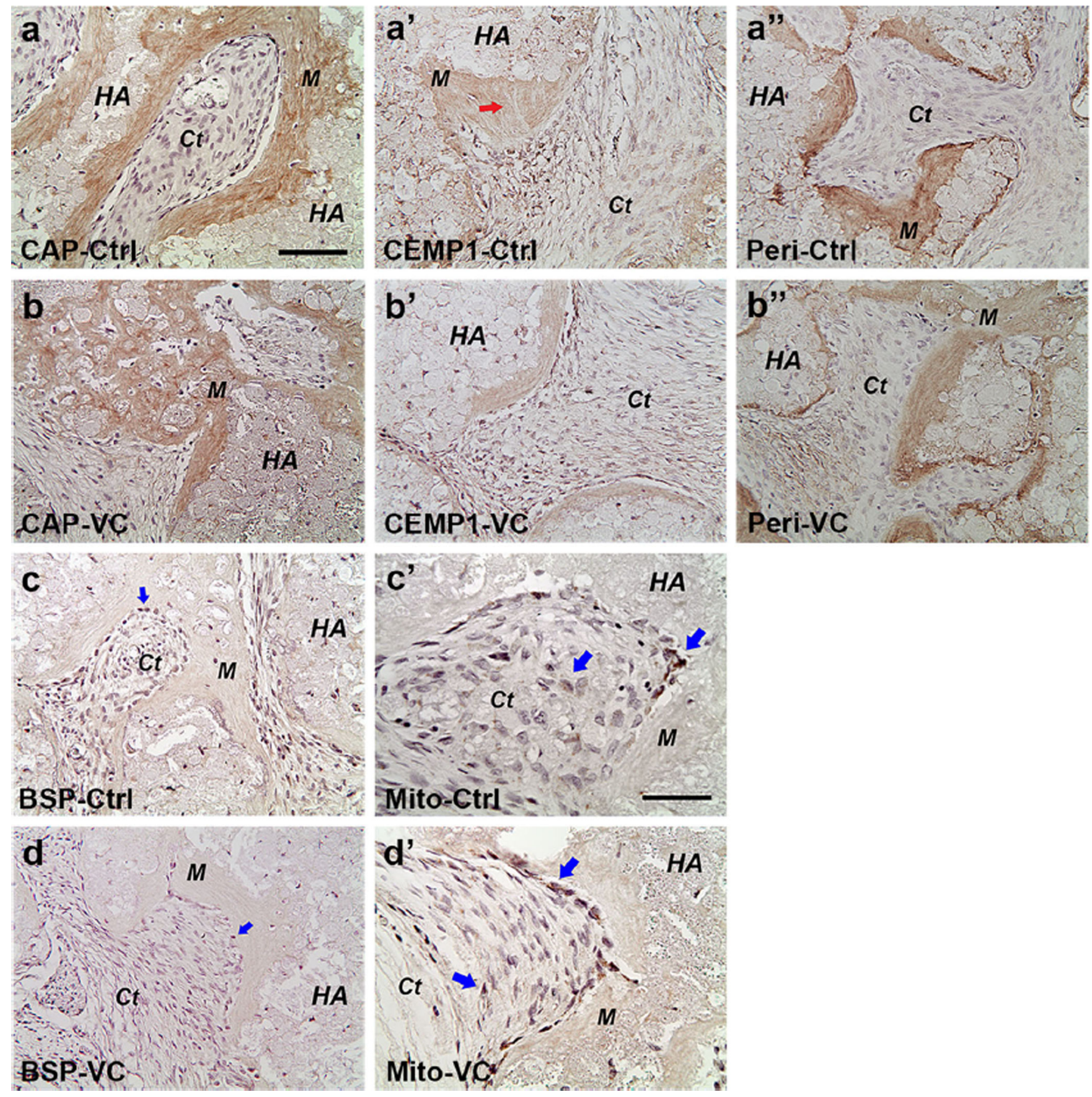

Fig. 6.

Immunohistochemical analysis of ectopic tissues regenerated in vivo by PDLSCs. Specific antibodies against human CAP (a, b), CEMP1 ( $\left.\mathbf{a}^{\prime}, \mathbf{b}^{\prime}\right)$, periostin (a”, b'), BSP (c, d) and mitochondria (c', d') were used to detect these gene products in the tissues shown in Fig. 5. The same antibody dilutions and conditions were used to detect the antigens for both control $(C t r l)$ and VC-treated groups in the same donor. Positive staining is shown by brown stains in mineral tissue, soft connective tissue or in individual cells. HA: hydroxyapatite/tricalcium phosphate; $M$ mineral tissue; $C t$ fibrous connective tissue. Arrows: in the CEMP1 
group indicating Sharpey's fiber-like; in the $B S P$ group indicate some cells having weak staining; in the Mito (mitochondria) group, they indicate stronger staining in cells lining against the mineral tissue and weaker staining in cells in the adjacent soft connective tissue. Scale bars (CAP, CEMP1, periostin and BSP images) $100 \mu \mathrm{m}$; (Mito images) $50 \mu \mathrm{m}$ 